\title{
Investigation on PCD cutting edge geometry for Ti6Al4V high feed milling
}

\author{
Anna Carla Araujo, Guillaume Fromentin and Patrick Blandenet
}

November 5, 2020

\author{
A.C. Araujoaraujo@insa-toulouse.fr (a,b,c) \\ G. Fromentin (a) \\ P. Blandenet (d) \\ (a) Arts et Metiers Institute of Technology, LaBoMaP, UBFC, HESAM Uni-
} versité, Cluny, F-71250, France

(b) COPPE - UFRJ, Rio de Janeiro, Brazil (2010-2019)

(c) Institute Clement Ader - INSA Toulouse, France (after 2020)

(d) Saint Jean Tooling, Saint Jean d'Ardières, 69220, France

Some new research challenges are connected to new high feed milling tools, developed recently to reduce the cutting time. The main objective of this article is to analyze if PCD tools could be used for high feed face milling of Ti6Al4V. As its performance depends significantly on cutting edge geometry, different tool geometries were evaluated regarding tool life and cutting forces. Experimental investigations demonstrate that the tool profile, which has a discontinuity on chip flow direction along the cutting edge, presents an intense local tool wear and, consequently, a smaller tool life. The PCD tool having a straight edge have longer tool life but, contrarily to the carbide tool theory, local wear behavior on the cutting edge is not constant when depth of cut increases. The cutting force magnitude and it dynamic, affects drastically the tool life on PCD tools in milling and it is a limitation to the increase of the material removal rate. In conclusion, it is possible to use specific PCD tools for milling Titanium alloy in high feed with low depth of cut (smaller than $1 \mathrm{~mm}$ ), which it is not economically practicable.

High feed milling Cutting forces Tool life Titanium alloy PCD Tool

\section{Introduction}

Titanium alloys have been used in the aerospace industry due to its: high strength-to-weight ratio (around $260 \mathrm{~N} \cdot \mathrm{m} / \mathrm{kg}$ ), the need to reduce fuel consumption and emissions, and higher resistance to fracture under fatigue [1]. The most common titanium alloy is Ti6Al4V, originally developed for aircraft 
structural applications in the 50's, and now accounts for more than $50 \%$ of the titanium-alloy world market share. In medical applications they are also chosen because of its oxidation resistance and bio-compatibility to manufacture surgical tools, dental and orthopedic implants, cardiovascular stents, artificial valves, crane-facial plates and screws, constantly subjected to static and fatigue loads $[2]$.

The manufacturing of Ti6Al4V relies on casting and forging or, now-a-days, additive manufacturing (DED, SLM or EBM) followed by subsequent machining [3]. Machining titanium alloys it is not an easy task because a low heat dissipation causes very high temperatures near the cutting edge [4]. Ti6Al4V thermal conductivity is $7.1 \mathrm{~W} / \mathrm{m} . \mathrm{K}$ and specific heat around $553 \mathrm{~L} / \mathrm{kg} . \mathrm{K})$. Also, this material has low elastic modulus (110 GPa, compared to steel that is around $200 \mathrm{GPa}$ and high chemical activation that increase tool wear and produce tool vibration.

The tool material commonly used for Ti6 Al4V alloys is the tungsten carbide (WC-Co) using cutting speed not superior to $60 \mathrm{~m} / \mathrm{min}$. Higher cutting speed drastically grow tool flank wear [5]. For example, the tool life of the uncoated carbide tools on Ti6Al4V at speed of $150 \mathrm{~m} / \mathrm{min}$ was around 2 minutes in [6]. For higher cutting speed it is very important to develop advanced tool materials, as single-crystal diamond $[7,8]$ or Polycrystalline Diamond (PCD) [9]. Comparing carbide and diamond, for a similar surface finishing and same removal rate, the recommended cutting speed for uncoated WC-Co inserts stays between 40-80 $\mathrm{m} / \mathrm{min}$ while using PCD inserts around 120-160 $\mathrm{m} / \mathrm{min}$ [10].

Many studies were developed in machining Titanium alloy with PCD specially using different cutting fluid applications. In turning at high speed machining conditions (around $200 \mathrm{~m} / \mathrm{min}$ ) high-pressure coolant [11] is used to improve tool life. For milling process this application has not the same effect, as the fluid cannot properly achieve the cutting edge region. In this case, the options for the use of cutting fluid are: flood [12], MQL [13, 14] and cryogenic machining [15], a more expensive installation. In the present study it was chosen to focus using flood application as it is the most common in aerospace industry, who is pushing on new tools for reducing the cutting time.

High Feed Milling (HFM) is an option used in rough face milling to increase MRR (up to $1400 \mathrm{~cm}^{3} / \mathrm{min}$ ) on flat surfaces with a large area, as for producing moulds and dies, engine blocks, flanges and machine guide-ways [16].The tool holder for HFM have a low cutting edge angle $\kappa_{r}$ in order to produce smaller uncut chip thickness with the same depth of cut $[17,18]$. In this case, milling uses a high feed-per-tooth $(0.4-4 \mathrm{~mm} /$ tooth $)$ and cutting edge angles $\kappa_{r}$ from 5 to 30 deg. Now-a-days, with the evolution of tool materials and tool holders stability, HFM has been expanded in tool manufacturing industry.

Only very few articles used the classification of "HFM" for its publications, specially using PCD. Tilmann et al [19] produced surface texture using feed per tooth equal to $0.1 \mathrm{~mm}$ using a very low depth of cut $f_{z}=0.1 \mathrm{~mm}$ and a low cutting speed $(60 \mathrm{~m} / \mathrm{min})$ in which the values are not comparable to the main objective of enhancing productivity in HFM. Hintze et al article [20] choose the label "High Productivity Conditions" which used PCD to machine carbide 
workpiece using $f_{z}=0.03 \mathrm{~mm} / \mathrm{th}$, that also cannot be considered a high value, and Corduan et al used the term "High Performance Machining" with $f_{z}=0.15$ $\mathrm{mm} /$ th [21]. Sahu et al [22] defined the optimized cutting parameters with PCD in face milling using cutting speed $133 \mathrm{~m} / \mathrm{min}$, feed per tooth $0.13 \mathrm{~mm} / \mathrm{rev}$ and depth of cut $2 \mathrm{~mm}$. In this last case, even the parameters are similar, this article did not classified itself as HPM, but it very close parameters comparing to the cited ones.

For machining titanium alloy Ti6Al4V with carbide tools, it is shown that position angle have no impact on the force model and is economically advantageous by reducing the machining time with the same chip removal rate [23, 24]. Although there is no article analysing the same behavior using PCD. In the research developed for the present article, the main objective is study to possibilities of using PCD tool in face milling in HFM, characterized by a low cutting angle. Different tool geometries are proposed varying: the chamfer angle (and consequently the effective rake angle) and cutting edge radius. In order to compare the tools, different levels of feed per tooth and depth of cut were experienced. The experimental plan and set-up are presented and the results of cutting forces, tool life and tool wear are analyzed.

\section{High feed face milling and force modelling}

Face milling is widely used in the early operations of a machining design, it can eliminate other processes using a more robust tool with a greater capacity to remove material with less vibration, compared to end milling. Because high-feed milling aims to remove higher chip volume, manufacturers advise that this fact increase radial forces causing tool holder vibration, a good reason to predict forces and limit feed velocity [24].

Different models were developed for the calculation of machining forces in milling, as described in many articles based on Martellotti chip thickness model [25, 26], Armarego and Deshpande chip load model [27, 28] and similar ones [29]. Machining forces model [30] considers that there is one portion dependent on the chip load area and one proportional to cutting edge length. Each small portion of the cutting edge has length $d b$ and the machining force component i depends on the specific forces $K_{i}$, a function of the cutting speed $V_{c}$ and uncut chip thickness $h$, and edge specific forces $k_{i e}$ [31]. $D_{i}$ is the diameter of the circular trajectory described to the inner point of the cutting edge, the diameter of the inner envelope used to define the spindle speed $N$ based on the defined cutting speed $V_{c}$.

$$
d \vec{F}_{m}(\theta)=\left[\begin{array}{c}
K_{c}\left(h\left(\theta, \kappa_{r}\right), V_{c}\right) \\
K_{e}\left(h\left(\theta, \kappa_{r}\right), V_{c}\right) \\
K_{h}\left(h\left(\theta, \kappa_{r}\right), V_{c}\right)
\end{array}\right] \cdot h\left(\theta, \kappa_{r}\right) \cdot d b+\left[\begin{array}{c}
k_{c e} \\
k_{e e} \\
k_{h e}
\end{array}\right] . d b
$$

The uncut chip thickness $h$ is measured perpendicular to the cutting edge (Eq. 2), using Martellotti equation depends on the tool angle position $\theta$ (related to the tool rotation, angle between feed direction $x$ and radial cutting edge 
position) and tool cutting edge angle $\kappa_{r}$. The cutting length $b$ that, in this case, does not vary along the cutting edge, is calculated as a function of the depth of cut $a_{p}$ Eq. 4. The tool cutting edge angle $\kappa_{r}$, the lead angle [32], and the chip load area are shown in Fig. 1a.

$$
h\left(\theta, \kappa_{r}\right)=f_{z} \sin \left(\kappa_{r}\right) \sin (\theta)
$$

$h$ (when the cutting edge is aligned feed direction, $\left.\theta=90^{\circ}\right)=f_{z} \sin \left(\kappa_{r}\right)$

$$
d b=\frac{d z}{\sin \left(\kappa_{r}\right)} \Longrightarrow b=\frac{a_{p}}{\sin \left(\kappa_{r}\right)}
$$

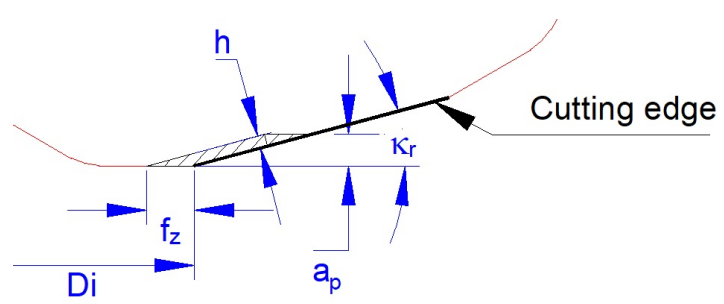

(a) Chip load area when the cutting edge is aligned feed direction $\left(\theta=90^{\circ}\right)$

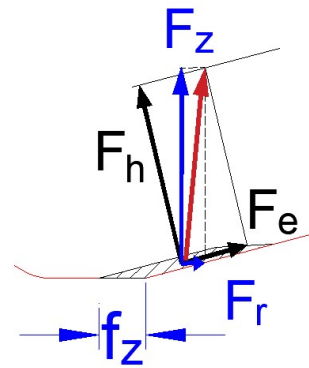

(b) Cutting force components

Figure 1: Cutting force model for face milling

As a result, the resultant machining force $\vec{F}_{m}$ is the sum of all $d F$ contributions: $F_{c}$ in the cutting direction, $F_{e}$ on the edge direction and $F_{h}$ perpendicular to the cutting edge, as shown in Figure 1b. In this article, the inclination angle will be neglected and the cutting force is approximately equal to the tangential force $\left(F_{t}=F_{c}\right)$. Also, the edge effect related to $k_{i e}$ values will be disregard as it is constant for all compared cases. In order to calculate the tangential components $F_{t}$, radial $F_{r}$ and vertical forces $F_{z}$ on the insert reference and the spindle tool axis oriented by the cutting angle $\kappa_{r}$ by making a reference frame (Fig. 1):

$$
\begin{aligned}
{\left[\begin{array}{l}
F_{c}(\theta) \\
F_{e}(\theta) \\
F_{h}(\theta)
\end{array}\right] } & =f_{z} \sin (\theta) a_{p}\left[\begin{array}{l}
K_{c} \\
K_{e} \\
K_{h}
\end{array}\right] \\
& = \\
& {\left[\begin{array}{ccc}
1 & 0 & 0 \\
0 & \cos \left(\kappa_{r}\right) & \sin \left(\kappa_{r}\right) \\
0 & -\sin \left(\kappa_{r}\right) & \cos \left(\kappa_{r}\right)
\end{array}\right]\left[\begin{array}{c}
F_{t} \\
F_{r} \\
F_{z}
\end{array}\right] } \\
& {\left[\begin{array}{ccc}
\sin (\theta) & \cos (\theta) & 0 \\
\cos (\theta) & -\sin (\theta) \sin \left(\kappa_{r}\right) & \sin \left(\kappa_{r}\right) \\
0 & -\sin \left(\kappa_{r}\right) & \cos \left(\kappa_{r}\right)
\end{array}\right]\left[\begin{array}{l}
F_{x} \\
F_{y} \\
F_{z}
\end{array}\right] }
\end{aligned}
$$


The local referential frame is used for modeling the forces $\left[F_{c}, F_{e}, F_{h}\right]$ and the workpiece referential frame, aligned with the machine-tool axis, for experimental data acquisition $\left[F_{x}, F_{y}, F_{z}\right]$. In order to evaluate the specific cutting force evolution, the experimental tangential force is used as a function of $f_{z}$ (as $\kappa_{r}$ is fixed) and $V_{c}$. For this evaluation, it is recommended to use the maximum cutting force along one revolution, that represents $F_{t}\left(\theta=90^{\circ}\right)$, when the insert is aligned with the feed direction:

$$
K_{c}\left(h, V_{c}\right)=\frac{F_{t}\left(\theta=90^{\circ}\right)}{f_{z} a_{p}}
$$

\section{Experiments}

The main objective of the experiments is to evaluate the influence of the cutting edge geometry in order to promote the longer tool life of the PCD machining Ti6Al4V Also, it is important to verify that the local behaviour on the tool wear is constant on the cutting edge, so the longer the cutting edge, maintaining the geometry, more productive the process with the same tool life. This section presents the conditions and characteristics of the experiments.

\subsection{Titanium alloy characterization}

The microstructure of machined material, an $\alpha+\beta$ alloy, consists on equiaxed $\alpha$ phase with average size of $20 \mu \mathrm{m}(7 \% \mathrm{Al}$ and $2 \% \mathrm{~V}$ wt. SEM spectrum) in a transformed $\beta$ phase $(5.5 \% \mathrm{Al}$ and $7.5 \% \mathrm{~V}$ wt. SEM spectrum). The microscopy is shown in Fig. 2. The measured hardness is $317 \pm 5 \mathrm{HV}(187.5 \mathrm{~g}$ load).

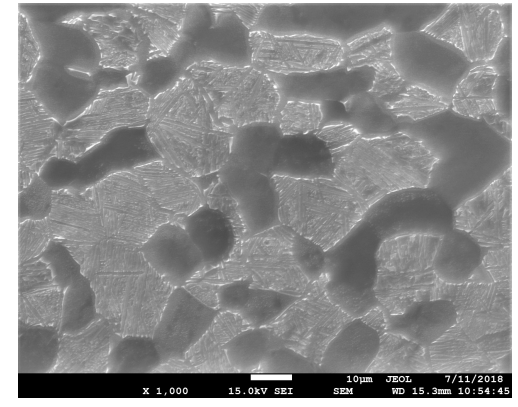

(a) $100 \times 100 \mu \mathrm{m}$

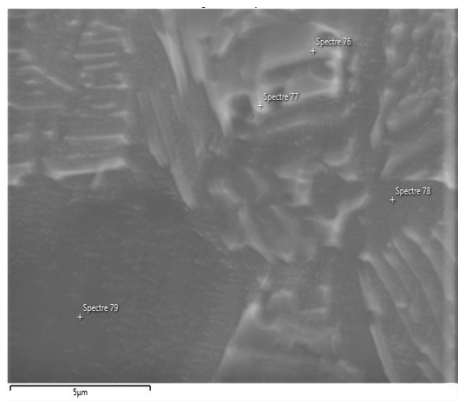

(b) $15 \times 15 \mu \mathrm{m}$

Figure 2: Micro structure of studied titanium alloy - Al 6.4\% V 4.6\% (wt.\%) 


\subsection{Insert manufacturing and PCD characterization}

The insert was manufactured by in some manufacturing steps by Saint Jean Industries ( $\mathrm{B}$. The PCD element is cut from a blank CMX580 PCD by Element Six $§$. It is characterized by sub-micron grain size, indicated by the supplier as ideal for milling and rough cutting of titanium alloys where extreme chip resistance is required. The microstructure and characterization of the PCD is analyzed by SEM JSM-761OF. The blank presents a PCD layer of $280 \mu \mathrm{m}$ thickness, as it can be seen in Fig. 3a. The PCD grain size is around $1 \mu \mathrm{m}$ in a WC-Co matrix (Fig. 3b). EDS confirmed that in the manufacturing process $\mathrm{PCD}$ was not contaminated as only $\mathrm{C}, \mathrm{W}$ and Co are present (Fig. 3c).

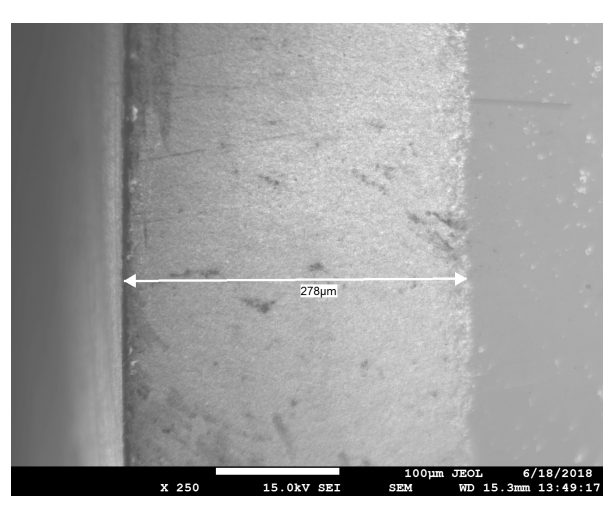

(a) Flank face

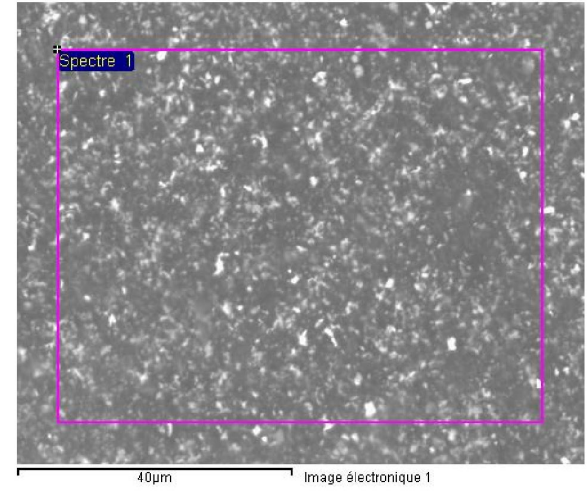

(b) Rake face

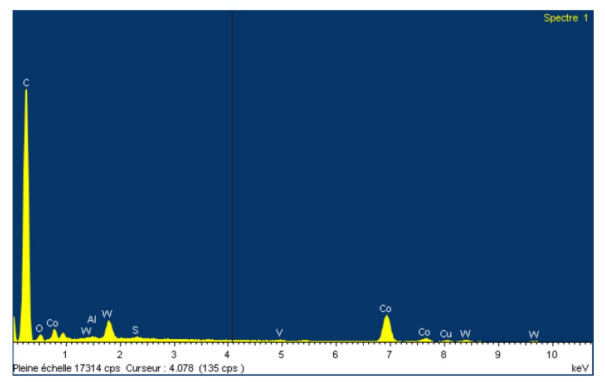

(c) Rake face EDS analysis

Figure 3: PCD characterization, done after the PCD insert is ready for use

In manufacturing step 1 is to produce a pocket using a carbide insert for logging the PCD element. Fig. 4a presents a commercial carbide insert with the pocket. After, in manufacturing step 2, a segment cut (by wire EDM) from 
the blank PCD is brazed over the carbide insert and cleaned with sandblasting. The set (carbide+PCD) is cut and grinded (manufacturing step 3) when the profile and chanfer on the cutting edge geometry are produced. The cutting edge radius after manufacturing step 3 is measured using Alicona Infinite Focus Measurement. In the first experiments, some tools received and extra-brushing step (manufacturing step 4) in order to increase the cutting edge radius.

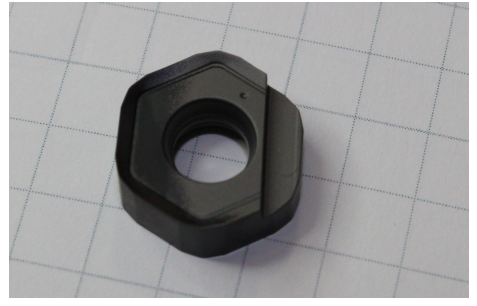

(a) Cutted carbide insert over a $20 \mathrm{~mm}$ squares paper (insert manufacturing step 1)

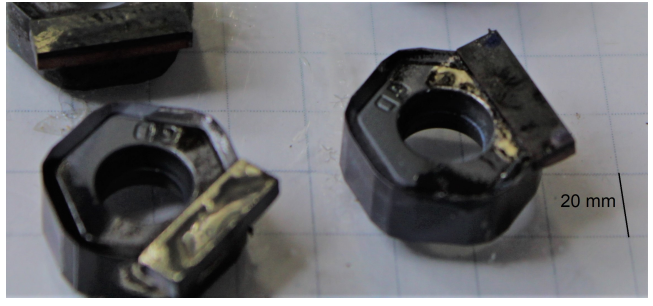

(b) PCD brazed insert over a $20 \mathrm{~mm}$ squares paper (after manufacturing step 2)

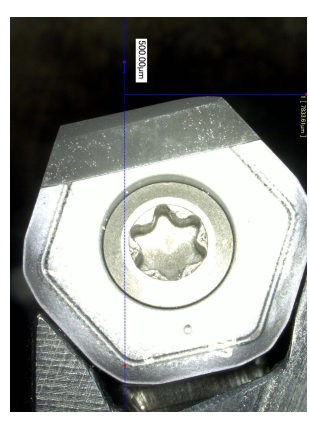

(c) Chamfer produced over the insert (manufacturing step 3)

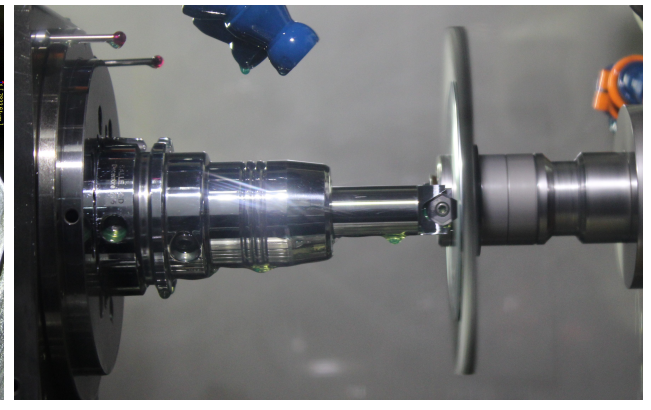

(d) Manufacturing step 4: brushing to increase cutting edge (*it was done only for some inserts in Geometry I)

Figure 4: Tool insert preparation 


\subsection{Machine-tool and cutting parameters}

A CNC DMC65V milling center is used to conduct experiments in flood condition: a $5 \%$ synthetic soluble cutting fluid with pressure and the flow rate respectively 40 bar and $23 \mathrm{~L} / \mathrm{min}$. The workpiece is fixed on a Kistler $9255 \mathrm{dy}-$ namometer attached to the machine-tool table and also the machine tool power consumption is collected. Tool trajectory considered the smooth entrance on the workpiece in order to reduce the insert damage that occurs on brittle material if the uncut chip thickness increase suddenly. Some first experiments did not took this prevention and it was notice that after a new tool entry a discontinuous wear increase was noted, so those experiments were discarded. It is important to notice that the tool life criteria is flank wear, but in some cases it was necessary to stop the tests before due to strong cutting edge damage.

The high feed milling tool support with $\kappa_{r}=15^{\circ}$ is used in industry with 3 inserts, nonetheless, in this work only one insert is used for the analysis of forces (Fig. 5). The axial insert angle is $7^{\circ}$, that will be neglected on force component modeling as it represents less than $10 \%$ of contribution in $F_{c}$. Special insert were realized for milling with PCD, i.e. carbide tool were pocketed in order to implement a PCD edge, as shown Fig 3. The PCD insert pocket in carbide insert is inclined $2^{\circ}$ in relation to the support cavity, so the effective rake angle $\gamma_{n}$ for each insert is calculate considering the slope of the pocket and the projection of the axial insert angle of the support slot, as a function of the chamfer rake angle $\gamma_{b}: \gamma_{n} \approx-\gamma_{b}+2^{o}-7^{o}=-\gamma_{b}-5^{o}$.

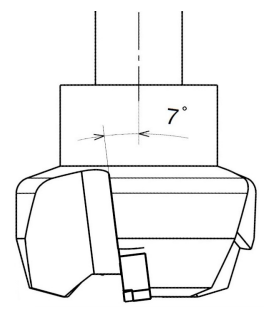

Figure 5: Tool support with axial insert angle $7^{\circ}$

Pre-tests are developed in order to define and confirm the cutting speed of $150 \mathrm{~m} / \mathrm{min}$, that remained constant for all the other experiments.

The planning of the experiments evolved over time during the research and three geometries of the cutting edge profile are designed for manufacturing (Fig. $6)$ :

- In the first experiments, Geometry I is designed to produce a straight cutting edge $\left(\kappa_{r}=15^{\circ}\right)$ with a small flat secondary cutting edge $\left(\kappa_{r}^{\prime}=0^{\circ}\right)$ to produce a smooth surface. The cutting edge point, joining major and minor cutting edge, is identified in Fig. 6 as $P_{c}$.

This first batch of experiments, using geometry I, the effect of cutting speed $(100-200 \mathrm{~m} / \mathrm{min})$, feed per tooth $(0.1-0.8 \mathrm{~mm} / \mathrm{th})$, the cutting edge 


\begin{tabular}{|l|l|l|l|}
\hline Experiments - Geometry I & Experiments - Geometry II \\
\hline $\begin{array}{l}\text { - Definition of } \mathrm{Vc} \text { and } \mathrm{fz} \\
\text { - Influence of cutting edge radius } \\
\text { - Influence of chamfer angle }\end{array}$ & $\begin{array}{l}\text { Experiments - Geometry III } \\
\text { - Influence of feed per tooth } \\
\text { - Influence of chamfer angle }\end{array}$
\end{tabular}

(a) Experiments with different Geometries

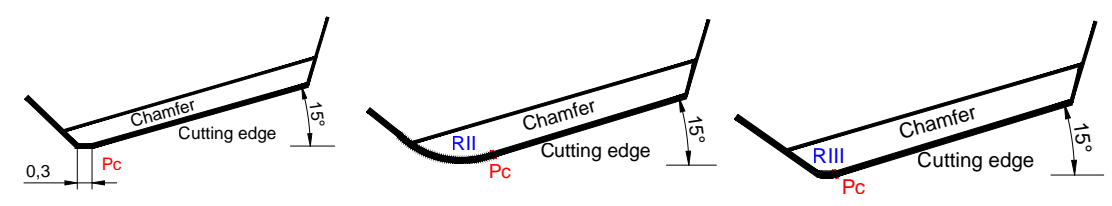
(b) Geometry I
(c) Geometry II
(d) Geometry III

Figure 6: Tool Profile Geometries

Table 1: Parameters used in all experiments (slot milling with $\kappa_{r}=15^{\circ}$ )

\begin{tabular}{|l|c|c|c|c|c|}
\hline $\begin{array}{l}\text { Geometry } \\
\text { Cutting edge profile }\end{array}$ & $\begin{array}{c}a_{p} \\
(\mathrm{~mm})\end{array}$ & $\begin{array}{c}f_{z} \\
(\mathrm{~mm})\end{array}$ & $\begin{array}{c}V_{c} \\
(\mathrm{~m} / \mathrm{min})\end{array}$ & $\begin{array}{c}\gamma_{n} \\
(\mathrm{deg})\end{array}$ & $\begin{array}{c}r_{\beta} \\
(\mu \mathrm{m})\end{array}$ \\
\hline \hline I & 0.50 & $0.1-0.8$ & $100-200$ & $\begin{array}{c}-5^{\circ} \\
-15^{\circ}\end{array}$ & $\begin{array}{c}5 \\
-25^{\circ}\end{array}$ \\
& & & & 15 \\
\hline II & 0.50 & $0.4-0.8$ & 150 & $-10^{\circ}$ & 5 \\
& & & & $-15^{\circ}$ & \\
& & & & $-20^{\circ}$ & \\
\hline III & 0.50 & 0.4 & 150 & $-15^{\circ}$ & 5 \\
& 0.75 & & & $-20^{\circ}$ & \\
\hline
\end{tabular}


radius $r_{\beta}\left(4^{\circ}-15^{\circ}\right)$ and the rake chamfer angle $\left(0-20^{\circ}\right)$ on the forces, cutting power and tool wear is studied.

This first geometry presented a upper limit to feed per tooth: when the length of the secondary cutting edge is smaller than the feed per tooth it produces a grooved surface.

- Geometry II is designed after testing geometry I, it was added a nose radius $r_{\epsilon}$ to the geometry $\left(R_{I I} \approx 10 \mathrm{~mm}\right)$ to reduce some problems desbribed on section 4 and also to explore a bigger range for rake chamfer angle from $0-20^{\circ}$. Using these inserts, the cutting speed was fixed to 150 $\mathrm{m} / \mathrm{min}$, varying feed per tooth.

- Geometry III design has a reduced tool radius $\left(R_{I I I} \approx 1 \mathrm{~mm}\right)$ and only two rake chamfer angles was tested $\left(15^{\circ}\right.$ and $\left.20^{\circ}\right)$ as per geometry II results. The third batch of experiments used fixed cutting speed, fixed feed per tooth and three values for depth of cut. Table 1 presents the conditions of all experiments.

It is important to reinforce that the parameters evolve to be more concentrated in the best values considering the partial results.

\section{Results and analysis}

\subsection{Specific cutting force results using Geometry I}

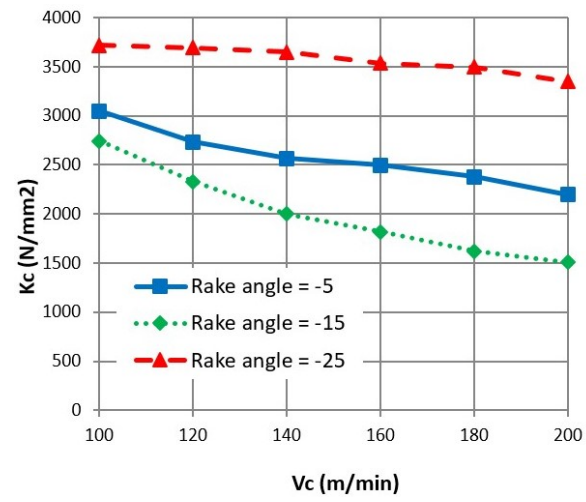

(a) Influence of $V_{c}$ and $\gamma_{n}\left(r_{\beta}=5 \mu m\right.$, $\left.f_{z}=0.4 m m / t h\right)$

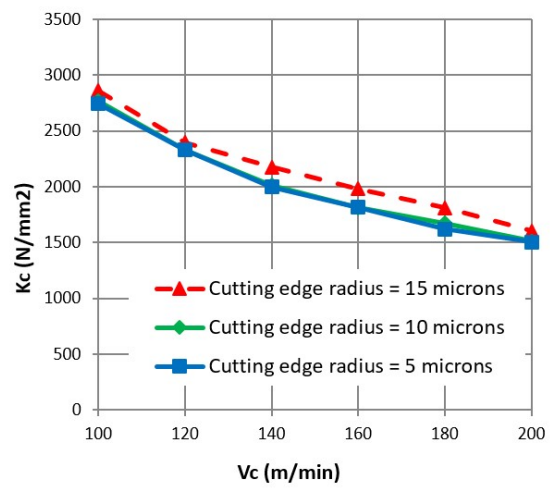

(b) Influence of $V_{c}$ and $r_{\beta}\left(\gamma_{n}=\right.$ $\left.-15^{\circ}, f_{z}=0.4 \mathrm{~mm} / \mathrm{th}\right)$

Figure 7: Influence of rake angle $\gamma_{n}$ and cutting edge radius $r_{\beta}$ on specific cutting force for geometry I 
The first experiments were developed using with geometry I. The first step is the confirmation of the chosen cutting speed for all tests. Figure 7 presents the curves for the inserts having the three different $\gamma_{n}$ and the three different $r_{\beta}$. Based on the distribution of specific cutting force curves and the French Standard procedure VF-E66-520-1 [33], the cutting speed $V_{c}=150 \mathrm{~m} / \mathrm{min}$ is chosen for the experiments using the next phases.

Figure 8 presents the curves changing the feed per tooth. It is clear that $\gamma_{n}=-15^{\circ}$ presented the lower specific cutting force $K_{c}$ for all cutting speeds and feeds. Regarding the cutting edge radius, the geometry without additional grinding $\left(r_{\beta}=5 \mu \mathrm{m}\right)$ presented the lower specific cutting force on all cases. As a result, the tools manufactured after this results (Geometry II and III) present the cutting edge radius produced by manufacturing step $3\left(r_{\beta}=5 \pm 2 \mu \mathrm{m}\right)$.

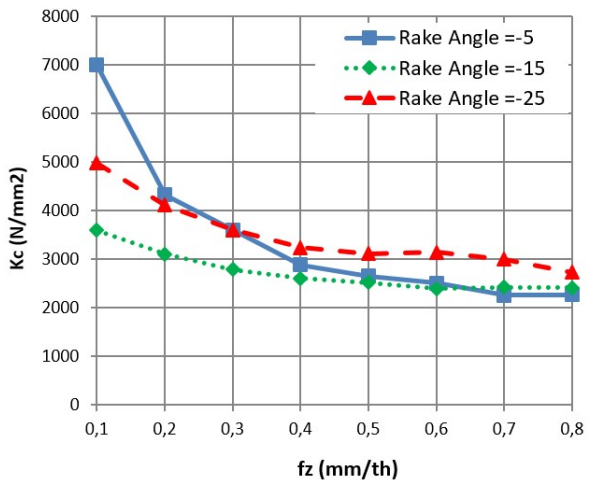

(a) Influence of $f_{z}$ and $\gamma_{n}\left(r_{\beta}=5 \mu \mathrm{m}\right.$, $V_{c}=150 \mathrm{~m} / \mathrm{min}$ )

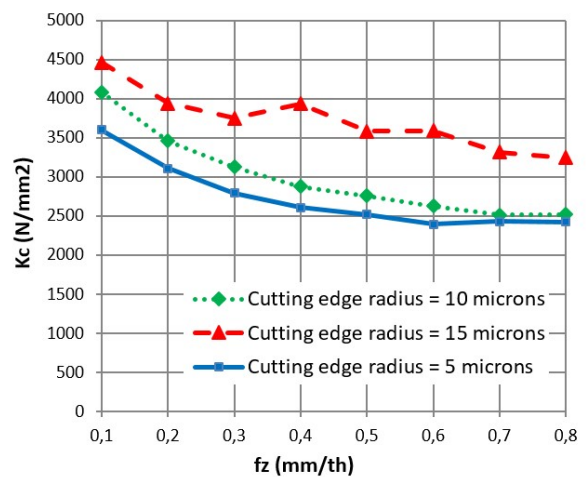

(b) Influence of $f_{z}$ and $r_{\beta}\left(\gamma_{n}=-15^{\circ}\right.$, $V_{c}=150 \mathrm{~m} / \mathrm{min}$ )

Figure 8: Influence of rake angle $\gamma_{n}$ and cutting edge radius $r_{\beta}$ on specific cutting force for geometry I

\subsection{Wear results using Geometry I}

Some inserts of geometry I $\left(\gamma_{n}=-15^{\circ}\right.$ and $\left.-25^{\circ}\right)$ are used to proceed with tool wear experiments using $f_{z}=0.4 \mathrm{~mm} / \mathrm{th}$. It is confirmed that the insert having $\gamma_{n}=-15^{\circ}$ presented the best performance with 21 min tool life (and $180 \mathrm{~cm}^{3}$ removed volume). A insert with the same rake angle was tested with $f_{z}=0.8 \mathrm{~mm} / \mathrm{th}$ and the same depth of cut and the tool remains only $5 \mathrm{~min}$ (approx. $50 \mathrm{~cm}^{3}$ ), as shown in Figure 8a. It was noted that in all cases, the tool wear was developed mainly from the nose cutting edge point $(\mathrm{Pc})$. Figure $8 \mathrm{~b}$ and $8 \mathrm{c}$ shows one of the last passes.

As the flat secondary cutting edge is constantly in contact to the piece, heat is additionally generated by friction combined with angular edge profile, 


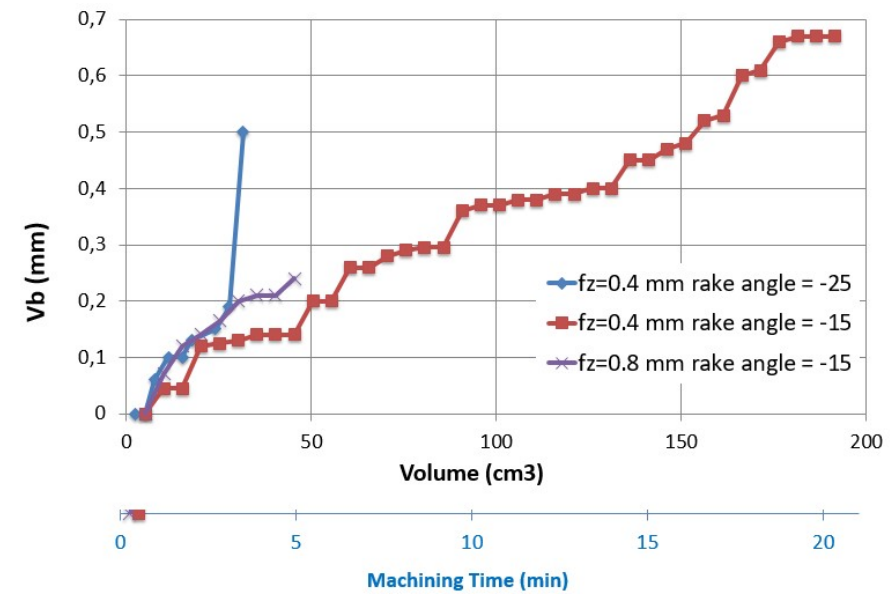

(a) Flank wear evolution

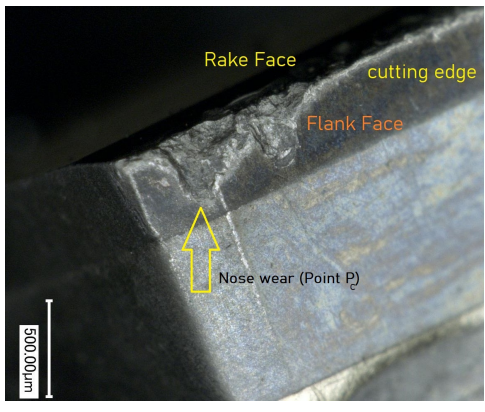

(b) Nose wear

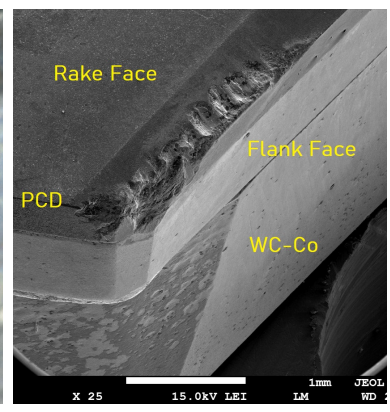

(c) Wear image (SEM)

Figure 9: Wear experiment using geometry I tools: $\gamma_{n}=-15^{\circ}\left(f_{t}=0.4 \mathrm{~mm} / \mathrm{th}\right.$ and $0.8 \mathrm{~mm} / \mathrm{th})$ and $-25^{\circ}\left(f_{t}=0.4 \mathrm{~mm} / \mathrm{th}\right), V_{c}=150 \mathrm{~m} / \mathrm{min}$. 
it would explain why the wear is higher in this region. Also, the size of the flat cutting edge was a limitation to the feed per tooth. For the feed per tooth higher than $0.3 \mathrm{~mm}$, the tool produced marks on the back side of the trajectory (as it is continuously in contact to the machined surface). That is the reason for changing the shape for geometry II. The curve could reduce this source of wear and improve tool life.

\subsection{Wear results using Geometry II}

For tool geometry II, in addition to a modified shape, the rake angle manufactured values were chosen around the best result for geometry I $\left(\gamma_{n}=\right.$ $-10,-15,-20)$. Also, as the additional grinding enhance the tool cost and does not improves the tool behavior, this manufacturing step is not used for manufacturing Geometries II and III so the cutting edge radius is $5 \pm 0.5 \mu \mathrm{m}$.

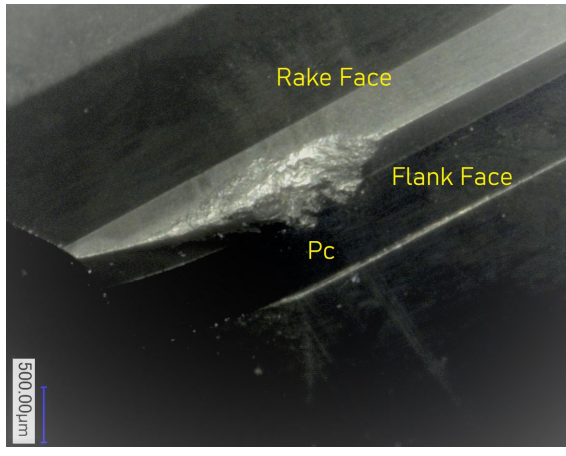

(a) Severe wear located at Pc

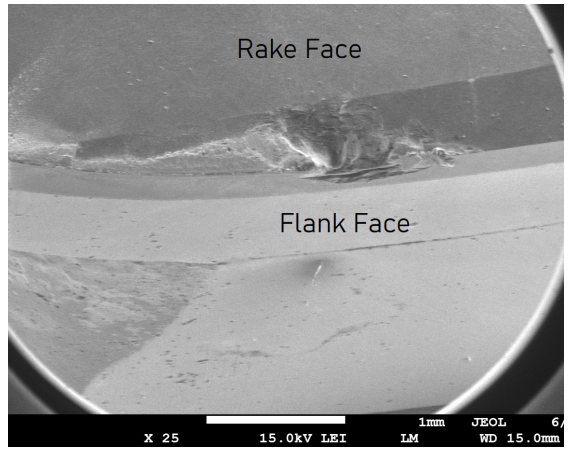

(b) Tool wear image (SEM)

Figure 10: Wear observation on geometry II tools: $\gamma_{n}=-10^{\circ}$ and $-20^{\circ}$

The tool life using geometry II were drastically smaller, comparing to the results presented using geometry I. in the point $\mathrm{Pc}$, where the tool nose ends. The flank wear VB with $\gamma_{n}=-10^{\circ}$ and $\gamma_{n}=-20^{\circ}$ tools were higher comparing to $\gamma_{n}=-15^{\circ}$ for the same cutting time. Tool life were less than $4 \mathrm{~min}\left(35 \mathrm{~cm}^{3}\right)$ using $\gamma_{n}=-10^{\circ}$ and $7 \mathrm{~min}\left(50 \mathrm{~cm}^{3}\right)$ using $\gamma_{n}=-20^{\circ}$. In Figure 9 , it can be seen that the tool wear was higher on the point of shape change $(\mathrm{Pc})$. The images suggest that the change on chip flow direction due to the change of shape on the cutting edge causes rake face crater on Pc. 


\subsection{Wear results using Geometry III}

The envelope shape for geometry III presents a reduced nose radius, compared to geometry II. It was noted that near the point Pc (Fig. 6b) the tool wear was clearly higher (Fig 9c). In this point, the local chip flows direction changes as it is guided by the cutting edge direction. Reducing the nose radius, this point is closer to the secondary cutting edge and the behavior is more similar to Geometry I except to the presence of the flat surface. Only two rake angles were tested: $\gamma_{n}=-15^{\circ}$ and $\gamma_{n}=-20^{\circ}$, using the same feed per tooth $\left(f_{z}=0.4\right.$ $\mathrm{mm} / \mathrm{th}$ ). In order to use a longer part of the cutting edge and enhance the chip volume, depth of cut were explored: $0.5,0.75$ and $1 \mathrm{~mm}$.

The results were very poor for higher depth of cut, as it is shown in Fig. 10a, what would not be expected if it is considered that the local behaviour does not influence the global tool wear behaviour. The resultant force $F_{x y}=\sqrt{F_{r}^{2}+F_{t}^{2}}$ and specific force $K_{c}$ were analyzed and the results are presented in Fig. 10b and 10c, respectively. It is deduced that as soon as the specific cutting force overpasses $1500 \mathrm{MPa}$, the tool arrives to the end of life. 


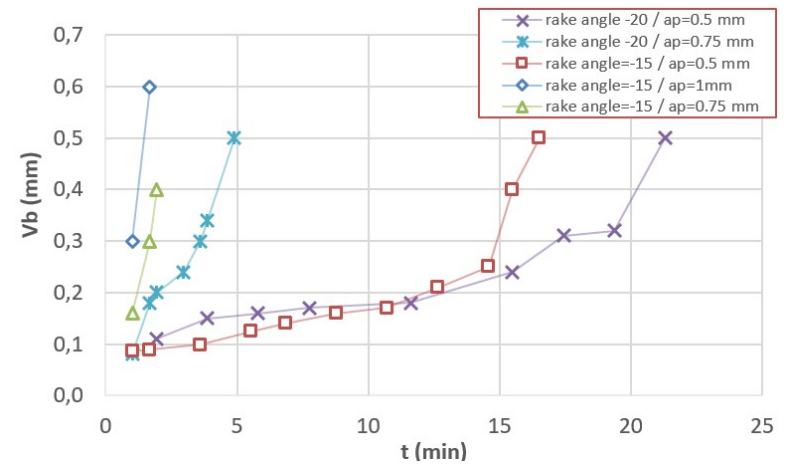

(a) Flank wear evolution

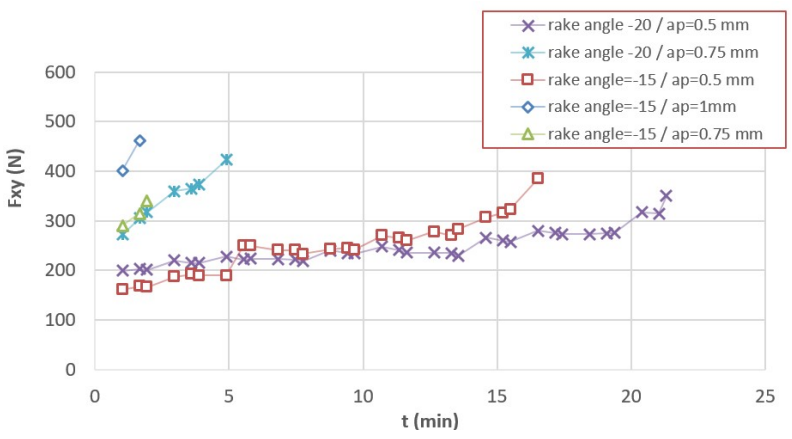

(b) Average force $F_{x y}$ evolution

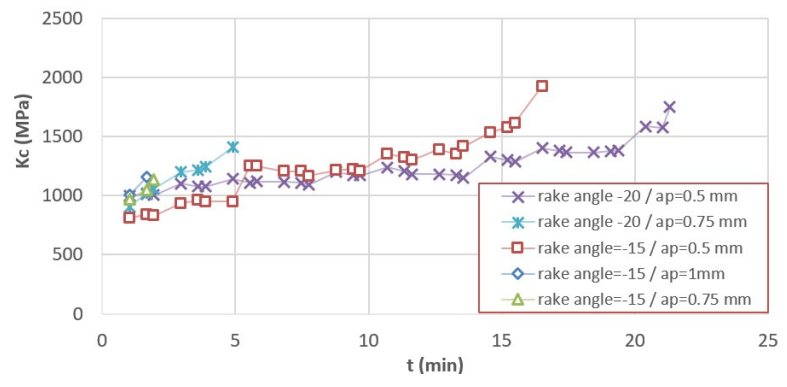

(c) Specific cutting force evolution

Figure 11: Wear behavior using geometry III tools 
Fig. 11 shows images of the tools after the experiments. Fig. 11a and 11b shows that using geometry III the cutting edge wears in all extension. The reduction of tool nose radius in this case was beneficial for the tool. Also it may be claimed that the tool wear is different comparing to Fig.10c, where microcracks can be noted on the tool. The cracks could be associated to the high machining force achieved with a quick intense tool wear appearance after a short cutting time $(1 \mathrm{~min})$. The higher amplitudes of cutting forces enhanced tool vibration and could probably have contribute to the appearance of the micro cracks.

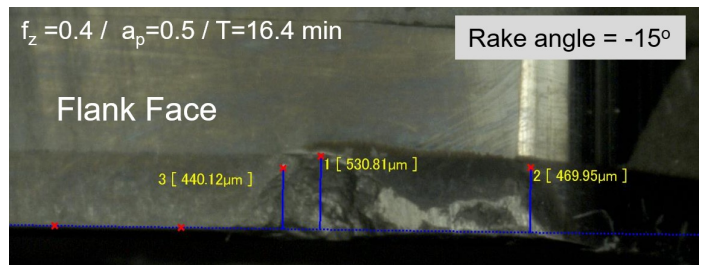

(a) $a_{p}=0.5 m m, t=16 m m, \gamma_{n}=-15^{\circ}$

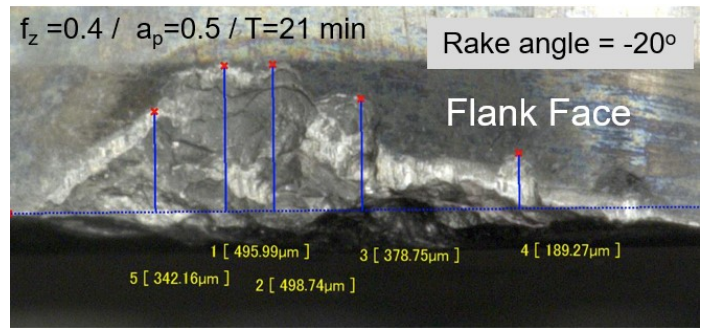

(b) $a_{p}=0.5 m m, t=21 m m, \gamma_{n}=-20^{\circ}$

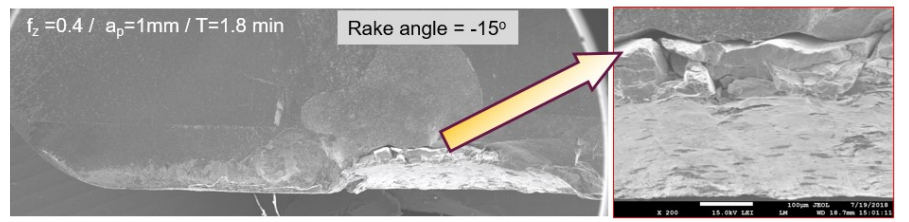

(c) $a_{p}=1 m m, t=1 m m, \gamma_{n}=-15^{\circ}$

Figure 12: Wear observation on geometry III tools

As per availability of new inserts, a final experiment was developed placing three inserts with $\gamma_{n}=-15^{\circ}$ at the same support. It was used the best conditions for this geometry: $f_{z}=0.4 \mathrm{~mm} /$ th and $a_{p}=0.5 \mathrm{~mm}$. Tool life achieved 


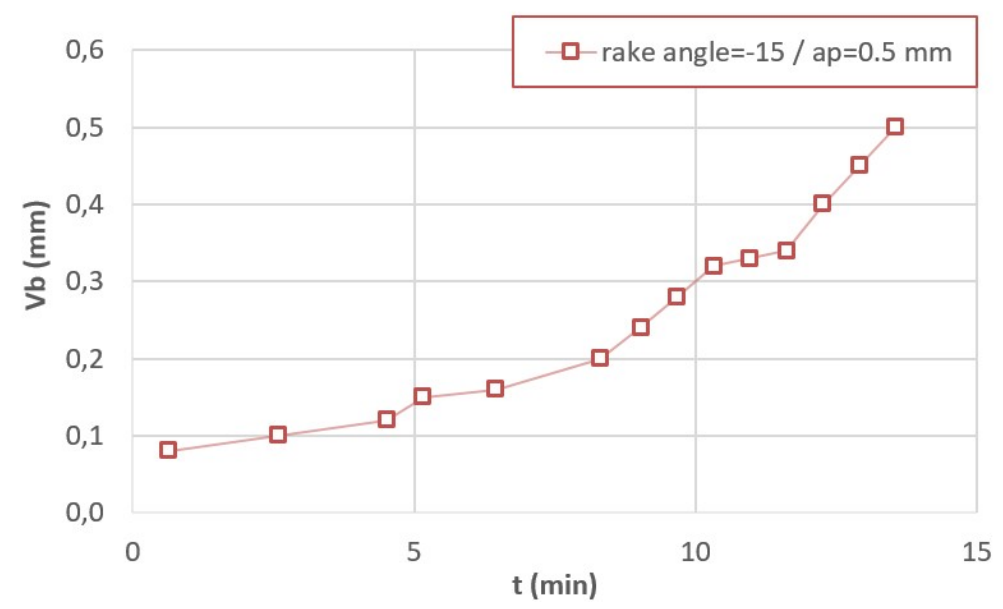

(a) Average flank wear from three inserts

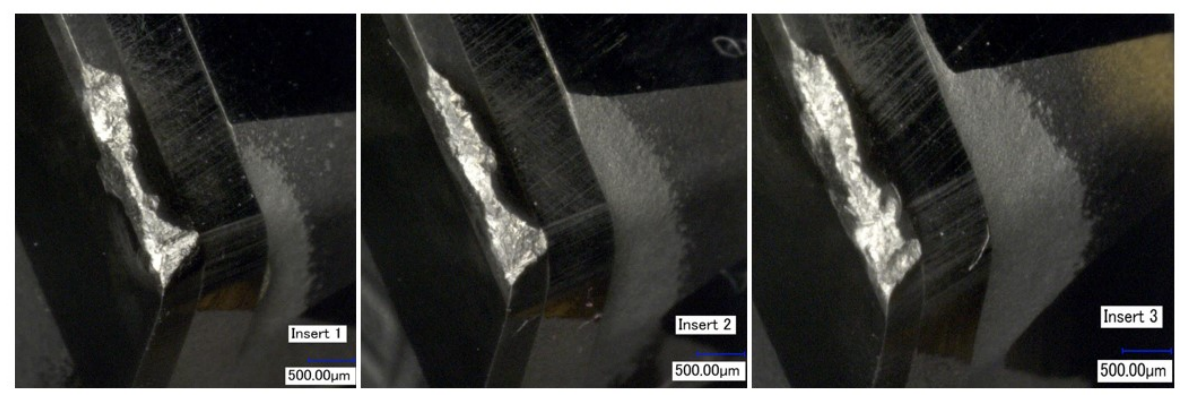

(b) Tool wear in three inserts

Figure 13: Tool wear using the three inserts on the tool support using geometry III 
was $13.5 \mathrm{~mm}$ with a volume of $345 \mathrm{~cm}^{3}$. Results for three inserts experiments are shown in Fig. 12. 


\subsection{Raman spectra results}

The Raman spectra of a new PCD insert and the two inserts presented in Fig. 12a and Fig. 12b were analyzed in a Witec alpha 300 micro-ramam confocal with $795 \mathrm{~nm}$ wavelenght. It can be seen in Raman results (Fig. 13) that D band (disorder) in $1330 \mathrm{~cm}^{-1}$, characteristic of amorphous carbon is present in the new tool and it is absent on the used tools. The $\mathrm{G}$ band $\left(1580 \mathrm{~cm}^{-1}\right)$ peak, related to the ordered graphite domains, observed on the spectrum obtained for the used tools is higher comparing to ones for the new one. These results could indicate that there occurred graphitization on used tools as it is also reported by $[21]$.

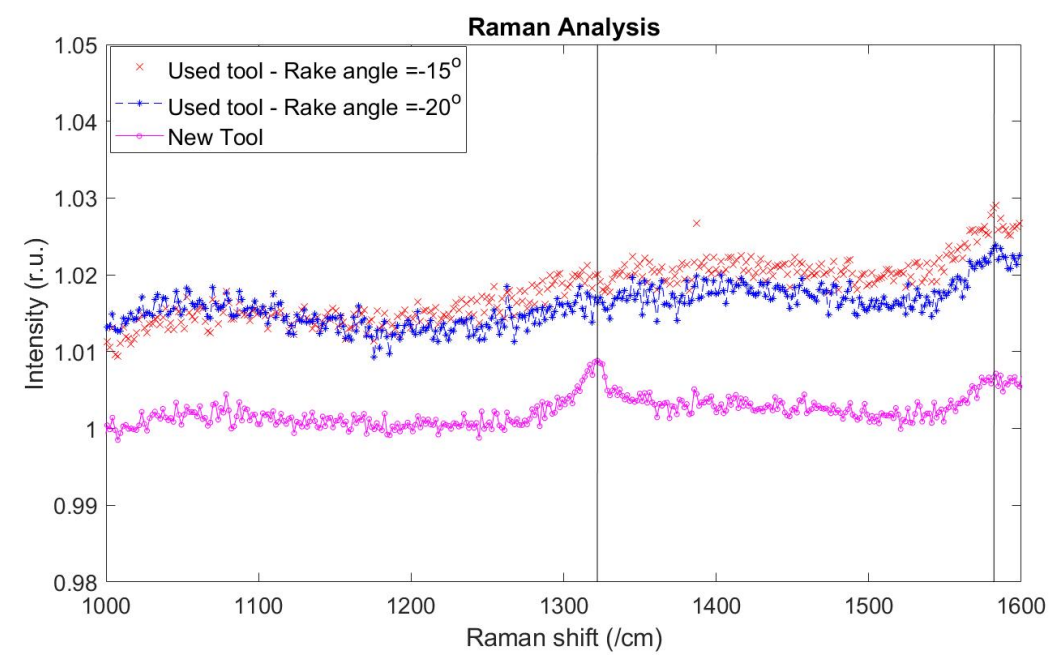

Figure 14: Comparative Raman analysis on three PCD inserts

\section{Conclusions}

This article is a new contribution to high feed milling technology as there is very few scientific studies, specially using a PCD tool. It is presented different customized tool geometries of CMX580 PCD cutting edge. The inserts were designed in order to analyze the influence of the rake angle and the tool profile on the specific cutting force and tool wear. The cutting parameters varied to explore and define the design of experiments. The insert geometry and the chip load area affected drastically tool life, without a regular behavior along the cutting edge. Some conclusions can be highlighted:

- The optimized cutting speed is defined as $150 \mathrm{~m} / \mathrm{min}$;

- A sharp nose radius (Geometry I) produced a rough surface in workpiece 
and presented relevant nose wear compared to the small nose radius (Geometry III);

- The lower PCD cutting edge radius $(5 \mu m)$ present the lower power and produced the lower specific cutting force comparing to larger radius in the same conditions;

- A punctual direction change on the cutting edge promoted a localized wear due to the chip flow change due to its shape;

- The optimized effective rake angle found on the customized tool is $-15 \mathrm{deg}$ for the analyzed conditions;

- The increasing of the cutting force, and consequently the amplitude for its dynamics, limited drastically the tool life, despite maintaining the specific cutting force constant. Micro-cracks on the rake surface appeared in the cases the cutting force over passed the value of approximately $400 \mathrm{~N}$ in average cutting force and $1000 \mathrm{~N}$ in maximum cutting force.

- Raman analysis on wear location did not present typical $s p^{3}$ diamond band, indicating the loss of this crystallographic structure and consequently its wear resistance.

As perspective for future research, a tribological study using PCD insert should be done to understand the reason for changing the behavior along the cutting edge using the same specific cutting force. This study will be important to make this application economically viable. In addition, two other aspects are important: a comparison between different cooling methods as MQL, combination of cutting fluids and cryogenic method, and the surface integrity: surface roughness and induced hardened layer, very important to the performance of the Ti-alloy parts.

\section{References}

[1] E. Ezugwu and Z. Wang, "Titanium alloys and their machinability-a review," Journal of Materials Processing Technology, vol. 68, no. 3, pp. 262 - 274, 1997. Superplasticity and Superplastic Technology in Japan.

[2] V. Parmar, A. Kumar, G. V. Prakash, S. Datta, and D. Kalyanasundaram, "Investigation, modelling and validation of material separation mechanism during fiber laser machining of medical grade titanium alloy ti6al4v and stainless steel ss3161," Mechanics of Materials, vol. 137, p. 103125, 2019.

[3] S. Liu and Y. C. Shin, "Additive manufacturing of ti6al4v alloy: A review," Materials Design, vol. 164, p. 107552, 2019.

[4] C. Machai, A. Iqbal, D. Biermann, T. Upmeier, and S. Schumann, "On the effects of cutting speed and cooling methodologies in grooving operation of various tempers of -titanium alloy," Journal of Materials Processing Technology, vol. 213, no. 7, pp. 1027 - 1037, 2013. 
[5] D.-W. Tan, Z.-W. Chen, W.-X. Wei, B.-C. Song, W.-M. Guo, H.-T. Lin, and C.-Y. Wang, "Wear behavior and mechanism of tib2-based ceramic inserts in high-speed cutting of ti6al4v alloy," Ceramics International, 2019.

[6] S. H. I. Jaffery and P. T. Mativenga, "Wear mechanisms analysis for turning Ti-6Al-4V - towards the development of suitable tool coatings," The International Journal of Advanced Manufacturing Technology, vol. 58, no. 5-8, pp. 479-493, 2012.

[7] W. Zong, D. Li, T. Sun, K. Cheng, and Y. Liang, "The ultimate sharpness of single-crystal diamond cutting tools - part II: A novel efficient lapping process," International Journal of Machine Tools and Manufacture, vol. 47, no. 5, pp. $864-871,2007$. Tehran International Congress on Manufacturing Engineering (TICME2005).

[8] W. Zong, Z. Li, T. Sun, K. Cheng, D. Li, and S. Dong, "The basic issues in design and fabrication of diamond-cutting tools for ultra-precision and nanometric machining," International Journal of Machine Tools and Manufacture, vol. 50, no. 4, pp. 411 - 419, 2010. Design of Ultraprecision and Micro Machine Tools and their Key Enabling Technologies.

[9] G. Li, M. Z. Rahim, S. Ding, and S. Sun, "Performance and wear analysis of polycrystalline diamond (PCD) tools manufactured with different methods in turning titanium alloy Ti-6Al-4V," The International Journal of Advanced Manufacturing Technology, vol. 85, pp. 825 - 841, 2016.

[10] A. N. Amin, A. F. Ismail, and M. N. Khairusshima, "Effectiveness of uncoated wc-co and pcd inserts in end milling of titanium alloy-ti-6al-4v," Journal of Materials Processing Technology, vol. 192-193, pp. 147 - 158, 2007. The Seventh Asia Pacific Conference on Materials Processing (7th APCMP 2006).

[11] R. B. da Silva, A. R. Machado, E. O. Ezugwu, J. Bonney, and W. F. Sales, "Tool life and wear mechanisms in high speed machining of ti-6al-4v alloy with pcd tools under various coolant pressures," Journal of Materials Processing Technology, vol. 213, no. 8, pp. 1459 - 1464, 2013.

[12] N. Fang and Q. Wu, "A comparative study of the cutting forces in high speed machining of ti-6al-4v and inconel 718 with a round cutting edge tool," Journal of Materials Processing Technology, vol. 209, no. 9, pp. 4385 - 4389, 2009.

[13] C. M. Rao, S. S. Rao, and M. A. Herbert, "Development of novel cutting tool with a micro-hole pattern on PCD insert in machining of titanium alloy," Journal of Manufacturing Processes, vol. 36, pp. 93 - 103, 2018.

[14] C. M. Rao, S. S. Rao, and M. A. Herbert, "Influence of modified cutting inserts in machining of Ti-6Al-4V alloy using pcd insert," Materials Today: Proceedings, vol. 5, no. 9, Part 3, pp. 18426 - 18432, 2018. Materials Processing and characterization, 16th - 18th March 2018. 
[15] A. Shokrani, V. Dhokia, and S. T. Newman, "Investigation of the effects of cryogenic machining on surface integrity in cnc end milling of ti-6al-4v titanium alloy," Journal of Manufacturing Processes, vol. 21, pp. 172 - 179, 2016.

[16] D. Borysenko, B. Karpuschewski, F. Welzel, J. Kundrák, and C. Felhő, "Influence of cutting ratio and tool macro geometry on process characteristics and workpiece conditions in face milling," CIRP Journal of Manufacturing Science and Technology, vol. 24, pp. 1 - 5, 2019.

[17] J. Kundrak and C. Felho, "Topography of the machined surface in high performance face milling," Procedia CIRP, vol. 77, pp. 340 - 343, 2018. 8th CIRP Conference on High Performance Cutting (HPC 2018).

[18] T. Regnier, G. Fromentin, B. Marcon, J. Outeiro, A. D'Acunto, A. Crolet, and T. Grunder, "Fundamental study of exit burr formation mechanisms during orthogonal cutting of AlSi aluminium alloy," Journal of Materials Processing Technology, vol. 257, pp. 112 - 122, 2018.

[19] W. Tillmann, L. Hagen, D. Stangier, M. Paulus, M. Tolan, R. Sakrowski, D. Biermann, and D. Freiburg, "Microstructural characteristics of highfeed milled hvof sprayed wc-co coatings," Surface and Coatings Technology, vol. 374, pp. 448 - 459, 2019.

[20] W. Hintze, S. Steinbach, C. Susemihl, and F. Kahler, "HPC-milling of WC-Co cemented carbides with PCD," International Journal of Refractory Metals and Hard Materials, vol. 72, pp. 126 - 134, 2018.

[21] N. Corduan, T. Himbart, G. Poulachon, M. Dessoly, M. Lambertin, J. Vigneau, and B. Payoux, "Wear mechanisms of new tool materials for Ti6Al-4V high performance machining," CIRP Annals, vol. 52, no. 1, pp. 73 $-76,2003$.

[22] N. K. Sahu, A. Jaiswal, and M. Ali, "Application of newly developed algorithms for improving surface finish in face milling of Ti-6Al-4V," Materials Today: Proceedings, 2020.

[23] R. O. Henz, F. Campos, A. C. Araujo, and G. Fromentin, "Cutting forces in high feed milling," 25 International Conference for Mechanical Engineering COBEM - Uberlandia, Brazil, 2019.

[24] V. Gylienè and V. Eidukynas, "The numerical analysis of cutting forces in high feed face milling, assuming the milling tool geometry," Procedia CIRP, vol. 46, pp. 436 - 439, 2016. 7th HPC 2016 - CIRP Conference on High Performance Cutting.

[25] P. K. Baro, S. S. Joshi, and S. Kapoor, "Modeling of cutting forces in a face-milling operation with self-propelled round insert milling cutter," International Journal of Machine Tools and Manufacture, vol. 45, no. 7, pp. $831-839,2005$. 
[26] A. C. Araujo, G. Fromentin, and G. Poulachon, "Analytical and experimental investigations on thread milling forces in titanium alloy," International Journal of Machine Tools and Manufacture, vol. 67, pp. 28 - 34, 2013.

[27] E. Armarego and C. Epp, "An investigation of zero helix peripheral upmilling," International Journal of Machine Tool Design and Research, vol. 10, no. 2, pp. 273 - 291, 1970.

[28] E. Armarego and N. Deshpande, "Computerized end-milling force predictions with cutting models allowing for eccentricity and cutter deflections," CIRP Annals, vol. 40, no. 1, pp. 25 - 29, 1991.

[29] T. Matsumura and S. Tamura, "Cutting force model in milling with cutter runout," Procedia CIRP, vol. 58, pp. 566 - 571, 2017. 16th CIRP Conference on Modelling of Machining Operations (16th CIRP CMMO).

[30] W. Grzesik, Advanced Machining Processes of Metallic Materials - Theory, Modelling and Applications. Elsevier, 2016.

[31] T. Dorlin, G. Fromentin, and J.-P. Costes, "Analysis and modelling of the contact radius effect on the cutting forces in cylindrical and face turning of Ti6Al4V titanium alloy," Procedia CIRP, vol. 31, pp. 185 - 190, 2015. 15th CIRP Conference on Modelling of Machining Operations (15th CMMO).

[32] "International Standard ISO 30021 - Basic quantities in cutting and grinding. Part 1: Geometry of the active part of cutting tools - general terms, reference systems, tool and working angles, chip breakers," standard, International Organization for Standardization, Geneva, CH, 1982.

[33] AFNOR, "Norme française E66-520 - Domaine de fonctionnement des outils coupants," 2017. 